\begin{tabular}{|c|l|}
\hline Title & Kinetic Study of Metal Biosorption to a Brown A Iga, Kjellmaniella Crassiforia \\
\hline Author(s) & Seki, Hideshi; Suzuki, A kira \\
\hline Citation & $\begin{array}{l}\text { Journal of Colloid and Interface Science, 246(2), 259-262 } \\
\text { https://doi.org/10.1006/cis.2001.8090 }\end{array}$ \\
\hline Issue Date & 2002-02-15 \\
\hline Doc URL & http://hdl.handle.net/2115/44064 \\
\hline Type & article (author version) \\
\hline File Information & 2002a.pdf \\
\hline
\end{tabular}

Instructions for use 


\title{
Kinetic Study of Metal Biosorption to A Brown Alga,
}

\author{
Kjellmaniella crassiforia
}

\author{
HIDESHI SEKI AND AKIRA SUZUKI
}

Division of Marine Biosciences, Graduate School of Fisheries Sciences, Hokkaido University, Minato-cho 3-1-1 Hakodate 041-8611, Japan

(Abbreviated title: KINETICS OF METAL BIOSORPTION TO A BROWN ALGA) Hideshi Seki

Division of Marine Biosciences, Graduate School of Fisheries Sciences, Hokkaido University,

Minato-cho 3-1-1 Hakodate 041-8611, Japan

e-mail seki@elsie.fish.hokudai.ac.jp 


\begin{abstract}
A kinetic study of cadmium and lead biosorption to a brown alga, Kjellmaniella crassiforia, was carried out. The shrinking core model derived by M. Gopala Rao and A. K. Gupta (Chem. Eng. J. 24, 181, 1982) was modified and adapted for description of the rate process of cadmium and lead biosorption to the alga. The biosorption rate process was well described and average apparent diffusion coefficient of about $9^{\prime} 10^{-6} \mathrm{~cm}^{2} \mathrm{~s}^{-1}$ was found for both cadmium and lead ions. The value was 20 to 50 times higher than the apparent diffusion coefficients of cadmium and lead ions in strong-acid resins like Dowex 50W-X8.
\end{abstract}

Key Words: kinetics; biosorption; diffusivity; cadmium; lead; brown alga. 


\section{INTRODUCTION}

The aqueous-phase separation of toxic heavy metal ions by biosorption has attracted much attention in recent years. Biosorption employs inexhaustible, inexpensive, nonhazardous adsorptive materials, and generates low volumes of nonhazardous waste. Microorganisms (1-7), algae (8-12), and other types of biomass (13-20) have been investigated for use in this application. An abundant source potentially metal-sorbing biomass are marine algae. They are widely available and are ecologically acceptable. Moreover, marine algae can be used as biosorbents without intricate pretreatment such as centrifugation and immobilization.

In our previous study, the biosorption mechanism of divalent heavy metal ions to three types of brown algae, Macrocystis pyrifera, Kjellmaniella crassiforia, and Undaria pinnatifida, was elucidated (12). The biosorption of bivalent metal ions to brown algae was due to bivalent binding to carboxylic groups on alginic acid in brown algae. Brown algae contain about $30 \%$ of alginic acid on a dry-weight basis, and alginic acid contains about 4 mmol g${ }^{-1}$ of carboxylic groups. Thus, the adsorption capacities of the brown algae for bivalent metal ions were in the range of 0.4 to $0.6 \mathrm{mmol} \mathrm{g}^{-1}$ and were comparable or superior to those of traditional inorganic adsorbents. 
In the remediation process of metal contaminated aqueous environments, the treatment of a large quantity of contaminated water should be required. Thus, the adsorbents used in this application will be required to have a high adsorption rate as well as high adsorption capacity. Since the apparent adsorption rate depends on the size and shape of adsorbents, the diffusion coefficients of target metal ions in the adsorbents must be determined for the quantitative evaluation of adsorption rate.

The aim of this paper is to determine the diffusion coefficients of cadmium and lead ions in a brown alga, $K$. crassiforia, which has a high adsorption ability to bivalent metal ions (12). The shrinking core model (21) was modified and adapted for the description of the rate process of metal adsorption to the alga. Based on the modified model (22), the diffusion coefficients of cadmium and lead ions in the alga are determined. 


\section{MATERIALS}

Cadmium nitrate, lead nitrate, and sodium nitrate were obtained from Wako Pure Chemical Industries (Japan). They were used as received.

K. crassiforia $(K C)$ was collected in Funka Bay, Japan. A leaf of $K C$ (ca. 1 $\mathrm{m}$ in length and ca. $20 \mathrm{~cm}$ in width) was dried at room temperature for 3 days after collection. Then it was cut to suitable size (ca. $2 \times 2 \mathrm{~cm}-$ ca. $10 \times 10 \mathrm{~cm}$ ). The pieces of $K C$ were further dried at $60^{\circ} \mathrm{C}$ for 2 days and stored in a desiccator. 


\section{EXPERIMENTAL METHODS}

A piece of dried $\mathrm{KC}$ was weighed and washed with a $\mathrm{HNO}_{3}\left(0.01 \mathrm{~mol} \mathrm{dm}{ }^{-3}\right)$ solution. It was swollen in a $200 \mathrm{~cm}^{3}$ of $\mathrm{NaNO}_{3}\left(0.1 \mathrm{~mol} \mathrm{dm}{ }^{-3}\right)$ solution for 12 h. The $K C$ was removed from the solution and was suspended in another 450 $\mathrm{cm}^{3}$ of $\mathrm{NaNO}_{3}\left(0.1 \mathrm{~mol} \mathrm{dm}{ }^{-3}\right)$ solution with a nylon thread. The $\mathrm{pH}$ of the solution was adjusted to the desired value by $\mathrm{HNO}_{3}$. After thermal equilibrium was reached at $30^{\circ} \mathrm{C}, 50 \mathrm{~cm}^{3}$ of $\mathrm{Cd}\left(\mathrm{NO}_{3}\right)_{2}$ or $\mathrm{Pb}\left(\mathrm{NO}_{3}\right)_{2}$ solution containing $\mathrm{NaNO}_{3}\left(0.1 \mathrm{~mol} \mathrm{dm}{ }^{-3}\right)$ was added to the solution and mechanically stirred. Aliquots $\left(2 \mathrm{~cm}^{3}\right)$ of the solution were collected, periodically, for the determination of residual cadmium or lead concentration. The kinetic experiment was continued until the biosorption process reached the equilibrium (ca. $48 \mathrm{~h}$ ). The concentrations of cadmium and lead in the liquid phase were determined with an atomic absorption spectrophotometer (Hitachi A-1800).

After the kinetic experiments, the $K C$ piece was removed and the excess water on the surface was wiped with a filter paper. It was weighed and was introduced into a graduated cylinder $\left(50 \mathrm{~cm}^{3}\right)$ containing $30 \mathrm{~cm}^{3}$ of distilled water. The volume of wet $K C, V$, was determined from the difference between the volumes of water in the absence and in the presence of $K C$. Furthermore, 
the shape of $K C$ was traced on a section paper (ruled into 1-mm squares) to determine the projected area of wet $K C$, $S$. The average thickness of $K C$ in a wet state, $d$, was determined from the relationship, $d=V / S$. 


\section{RESULTS AND DISCUSSION}

\section{Solid Contents of KC pieces}

In this study, we intentionally used $K C$ pieces that have different average thicknesses $(0.12-0.2 \mathrm{~cm})$ to ensure the validity of adapted kinetic model and the accuracy of obtained diffusion coefficients. If the kinetic model used in this study would be appropriate, the model would give the same diffusion coefficient regardless of the average thicknesses of $K C$ pieces. However, it must be noted that the solid contents of $K C$ pieces should affect the apparent diffusion coefficients of metal ions.

The volume of the water in $K C$ pieces, $V_{w}$, was estimated from the following relationship;

$$
V_{w}=\left(m-m_{d}\right) / \rho_{w},
$$

where $m, m_{d}$ and $\rho_{w}$ are the wet weight of $K C$ pieces, the dry weight of $K C$ pieces and the density of water at $30^{\circ} \mathrm{C}\left(\rho_{w}=0.996 \mathrm{~g} \mathrm{~cm}^{-3}\right)$, respectively. The relation between the volume of wet $K C$ pieces, $V$, and the volume of the water in $K C$ pieces calculated from Eq.[1], $V_{w}$, was shown in Fig.1. A good linear relationship, the correlation coefficient of 1.00, was obtained between $V$ and 
$V_{W}$. The result shows that the water/solid contents of $K C$ pieces used in this study were almost constant regardless of the thickness. The average volume fraction of water was obtained from the slope of the regression line as 0.83 (SD: 0.040 ), that is, the volume fraction of solid in $K C$ pieces was only 0.17 .

\section{Kinetics of Metal Biosorption to KC}

Figures 2a and 2b show the time dependence of cadmium biosorption to $K C$ at the initial concentrations of cadmium $1.0 \times 10^{-4}$ and $2.0 \times 10^{-4} \mathrm{~mol} \mathrm{dm}^{-3}$, respectively. Figures $\mathbf{3 a}$ and $\mathbf{3 b}$ show the time dependence of lead biosorption to $K C$ at the initial concentrations of lead $4.0 \times 10^{-4}$ and $5.0 \times 10^{-4} \mathrm{~mol} \mathrm{dm}^{-3}$, respectively. The ordinate, $X_{t}$, denotes the amount of metal ions adsorbed to 1 $\mathrm{cm}^{3}$ of $K C$ at time $t$. The $\mathrm{pH}$ at equilibrium and the average thickness of $K C$ pieces in a wet state, $d$, were presented in the figures.

The shrinking core model was derived by Gopala Rao and Gupta to find the apparent diffusion coefficients of metal ions in spherical adsorbents (21). The model is based on the following assumptions: the adsorption rate process is controlled by the diffusion of adsorbate ions through the reacted shell in the adsorbent particles (particle diffusion control), and the shrinkage of unreacted shell is much slower than the mass transfer rate of adsorbate ions toward the unreacted surface. 
In our previous study, the shrinking core model was modified and adapted for description of the rate process of lead adsorption to a membranous adsorbent. The adsorbent (HA-M) was composed of three materials, humic acid, alginic acid, and activated carbon and it had the average thickness of $0.0216 \mathrm{~cm}$. The rate process of lead adsorption was well described and average apparent lead diffusion coefficients of about $7 \times 10^{-6} \mathrm{~cm}^{2} \mathrm{~s}^{-1}$ was found (22).

The area of unreacted shell surface in spherical adsorbents changes or shrinks with the extent of the adsorption process, while the area of unreacted layer surface in membranous adsorbents remains constant through the adsorption process. In addition, the metal ions can diffuse into the membranous adsorbent from two sides of flat slab. In the case of membranous adsorbents, therefore, the shrinking core model can be modified or simplified to the following expression:

$$
\left(\frac{X_{t}}{X}\right)^{2}=\frac{2 D}{X(d / 2)^{2}} \int_{0}^{t} C d t
$$

or

$$
\left(\frac{X d^{2}}{8}\right)\left(\frac{X_{t}}{X}\right)^{2}=D \int_{0}^{t} C d t
$$


where $C\left(\mathrm{~mol} \mathrm{~cm}^{-3}\right)$ is the concentration of metal ions in solution. $D\left(\mathrm{~cm}^{2} \mathrm{~s}^{-1}\right)$, $d(\mathrm{~cm})$, and $X\left(\mathrm{~mol} \mathrm{~cm}^{-3}\right)$ are the apparent diffusion coefficient of metal ions, average thickness of $K C$, and active site concentration in $K C$, respectively. If the biosorption process is controlled by the diffusion of metal ions through the reacted layer, a plot of $\left(X d^{2} / 8\right)\left(X_{t} / X\right)^{2}$ versus $\int_{0}^{t} C d t$ gives a straight line and the apparent diffusivity of metal ions in $K C$ can be obtained from the slope of the line.

Equation [2] was applied to the kinetic experimental data in Figs. 2a, 2b, 3a, and 3b. The results are shown in Figs. 4 and 5, respectively. The plots give straight lines that pass through the origin and demonstrate good agreement between the experimental data and the model expressed by Eq. [2]. The apparent diffusion coefficients of cadmium and lead ions in $K C$ were obtained from the slopes of the regression lines in Figs. 4 and 5 as $9.62 \times 10^{-6}$ and 9.51 $\times 10^{-6} \mathrm{~cm}^{2} \mathrm{~s}^{-1}$, respectively. These values are 20 to 50 times higher than the apparent diffusion coefficients of cadmium and lead ions in strong-acid resins like Dowex 50W-X8 (21) and the apparent diffusion coefficient of ferric ions in activated carbon (23), 2 to $5 \times 10^{-7} \mathrm{~cm}^{2} \mathrm{~s}^{-1}$.

The apparent diffusion coefficients of cadmium and lead ions in $K C$ determined in this study are rather close to those in the chelating resin Chelex 100 reported by Gopala Rao and Gupta, $2-6 \times 10^{-6} \mathrm{~cm}^{2} \mathrm{~s}^{-1}(21)$ and the 
apparent diffusion coefficient of lead ions in HA-M reported by the authors, about $7 \times 10^{-6} \mathrm{~cm}^{2} \mathrm{~s}^{-1}(22) . K C$, Chelex 100, and HA-M have the same metal binding sites, i. e. carboxylic groups, and the binding reactions of bivalent metal ions to these adsorbents are the same bivalent binding $(12,20,21)$. Thus the apparent diffusion coefficients of metal ions in $K C$ would be close to those in Chelex 100 and HA-M. 


\section{CONCLUSION}

A kinetic study of cadmium and lead biosorption to a brown alga, Kjellmaniella crassiforia, was carried out. The shrinking core model derived by Gopala Rao and Gupta was modified and adapted for the description of the rate process of cadmium and lead biosorption to a brown alga (average thickness of $0.15 \mathrm{~cm}$ ). The kinetic experimental data agreed well with the modified model. The apparent diffusion coefficients of cadmium and lead ions in the alga were estimated from the model. The apparent diffusion coefficients of about $9 \times 10^{-6} \mathrm{~cm}^{2} \mathrm{~s}^{-1}$ was determined for both cadmium and lead ions. 


\section{APPENDIX A: NOMENCLATURE}

C concentration of metal ions in solution $\left(\mathrm{mol} \mathrm{cm}^{-3}\right)$

$d \quad$ thickness of $K C$ in a wet state $(\mathrm{cm})$

$D$ apparent diffusivity of metal ions in $K C\left(\mathrm{~cm}^{2} \mathrm{~s}^{-1}\right)$

$m_{d} \quad$ weight of $K C$ in a dry state (g)

$m \quad$ weight of $K C$ in a wet state (g)

$S$ projected area of $K C$ in a wet state $\left(\mathrm{cm}^{2}\right)$

$t \quad$ time (s)

$V \quad$ volume of $K C$ in a wet state $\left(\mathrm{cm}^{-3}\right)$

$V_{W} \quad$ volume of water in $K C$ in a wet state $\left(\mathrm{cm}^{3}\right)$

$X \quad$ active site concentration in $K C\left(\mathrm{~mol} \mathrm{~cm}^{-3}\right)$

$X_{t} \quad$ amount of metal ions adsorbed at time $t\left(\mathrm{~mol} \mathrm{~cm}^{-3}\right)$

$\rho_{W}$ density of water $\left(\mathrm{g} \mathrm{dm}^{-3}\right)$ 


\section{REFERENCES}

1. Niu, H., Xu, X. S., Wang, J. H., and Volesky, B., Biotechnol. Bioeng. 42, 785 (1993).

2. Volesky, B., May, H., and Holan, Z. R., Biotechnol. Bioeng. 41, 826 (1993).

3. Chang, J., and Hong, J., Biotechnol. Bioeng. 44, 999 (1994).

4. Plette, A.C.C., Benedetti, M.F., and van Riemsdijk, W.H., Environ. Sci. Technol. 30, 1902 (1996).

5. Macaskie,L.E., Yong,P., Doyle,T.C., Roig,M.G., Diaz,M.,and Mnzano,T., Biotechnol. Bioeng. 53, 100 (1997).

6. Seki, H., Suzuki, A., and Mitsueda, S., J. Colloid Interface Sci. 197, 185 (1998).

7. Seki, H., and Suzuki, A., J. Colloid Interface Sci. 229, 196 (2000).

8. Holan, Z. R., Volesky, B., and Prasetyo, I., Biotechnol. Bioeng. 41, 819 (1993).

9. Holan, Z. R., and Volesky, B., Biotechnol. Bioeng. 43, 1001 (1994).

10. Volesky, B., and Prasetyo, I., Biotechnol. Bioeng. 43, 1010 (1994).

11. Chong, K. H., and Volesky, B., Biotechnol. Bioeng. 49, 629 (1996).

12. Seki, H., and Suzuki, A., J. Colloid Interface Sci. 206, 297 (1998).

13. Jang, L.K., Brand, W., Resong, M., and Mainieri, W., Environ. Prog. 9, 
269 (1990).

14. Jang, L.K., Geesey, G.G., Loopez, S.L., Eastman, S.L., and Wichlacz P.L. Water Res. 24, 889 (1990).

15. Seki, H., Suzuki, A., and Kashiki, I., J. Colloid Interface Sci. 134, 59 (1990).

16. Jang, L.K., Lopez, S.L., Eastman, S.L., and Pryfogle, P., Biotechnol. Bioeng. 37, 266 (1991).

17. Deans, J.R., and Dixon, G. Water Res. 26, 469 (1992).

18. Chen, D., Lewandowski, Z., Roe, F., and Surapaneni, P., Biotechnol. Bioeng. 41, 755 (1993).

19. Seki, H., and Suzuki, A., J. Colloid Interface Sci. 171, 490 (1995).

20. Seki, H., and Suzuki, A., Ind. Eng. Chem. Res. 35, 1379 (1996).

21. Gopala Rao, M. G., and Gupta, A. K., Chem. Eng. J. 24, 181 (1982).

22. Seki, H., and Suzuki, A., J. Colloid Interface Sci. 211, 375 (1999).

23. Onganer, Y., and Temur, Ç., J. Colloid Interface Sci. 205, 241 (1998). 


\section{Figure Captions}

FIG. 1. Relationship between the volume of $K C$ in a wet state and the volume of water in $K C$.

FIG. 2. Time dependence of cadmium adsorption to $K C$ at $30^{\circ} \mathrm{C}$. Initial concentrations of $\mathrm{Cd}\left(\mathrm{NO}_{3}\right)_{2}$ were (a) $1.0 \times 10^{-4}$ and (b) $2.0 \times 10^{-4} \mathrm{~mol} \mathrm{dm}^{-3}$, respectively.

FIG. 3. Time dependence of lead adsorption to $K C$ at $30{ }^{\circ} \mathrm{C}$. Initial concentrations of $\mathrm{Pb}\left(\mathrm{NO}_{3}\right)_{2}$ were (a) $4.0 \times 10^{-4}$ and (b) $5.0 \times 10^{-4} \mathrm{~mol} \mathrm{dm}{ }^{-3}$, respectively.

FIG. 4. Fitting of the data in Fig. 2 to Eq. [2].

FIG. 5. Fitting of the data in Fig. 3 to Eq. [2]. 


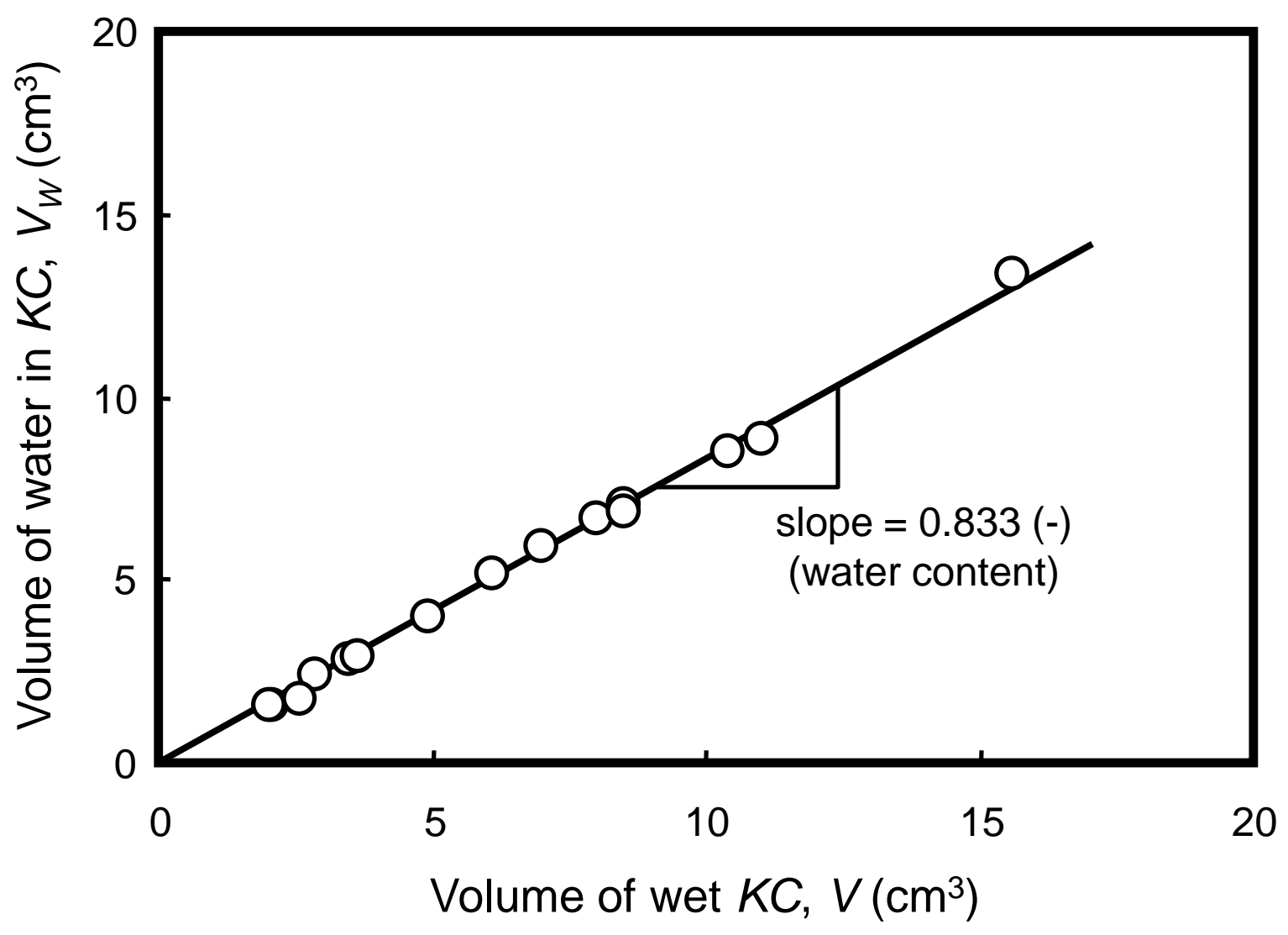

Seki \& Suzuki FIG. 1. 


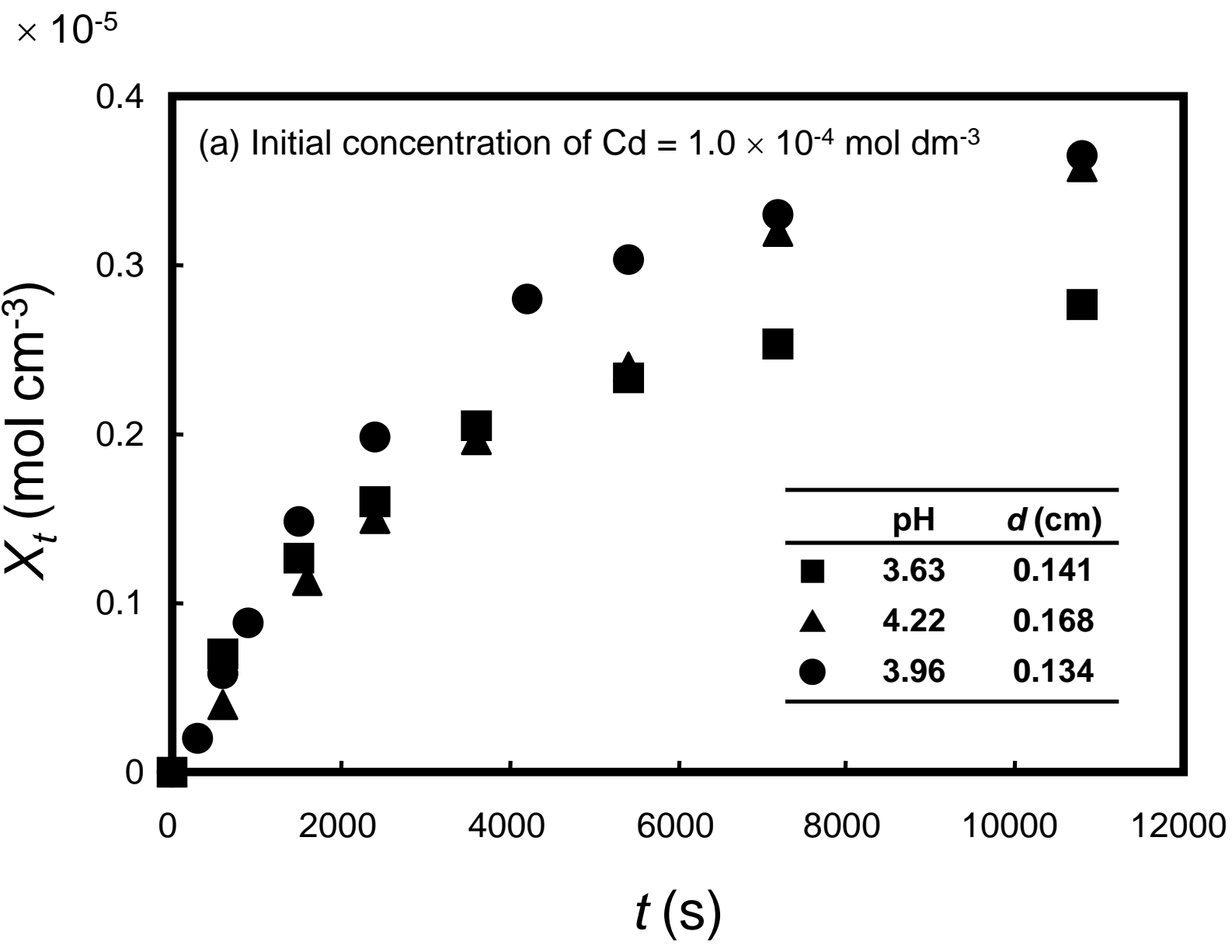

Seki \& Suzuki FIG. 2a. 


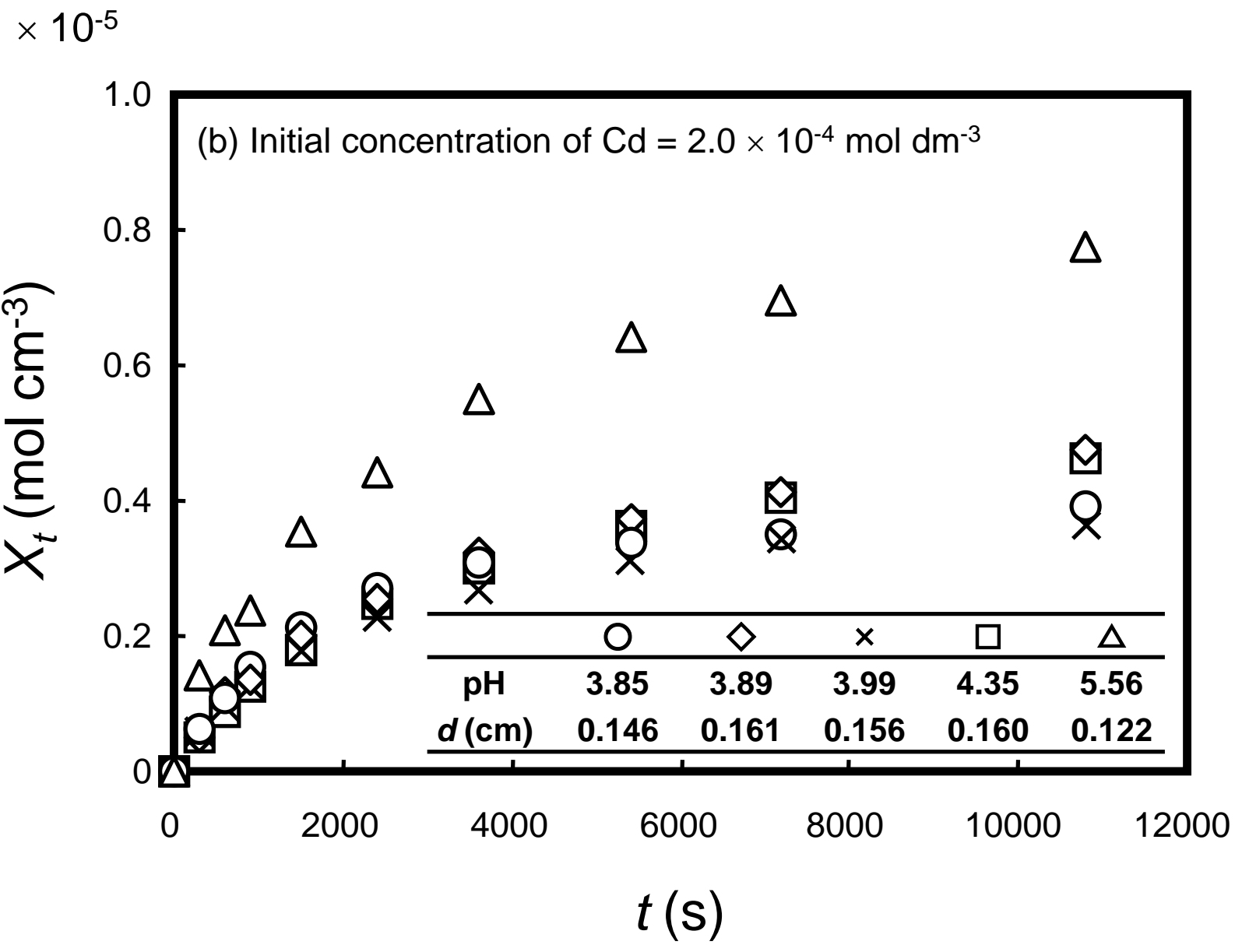

Seki \& Suzuki FIG. 2b. 


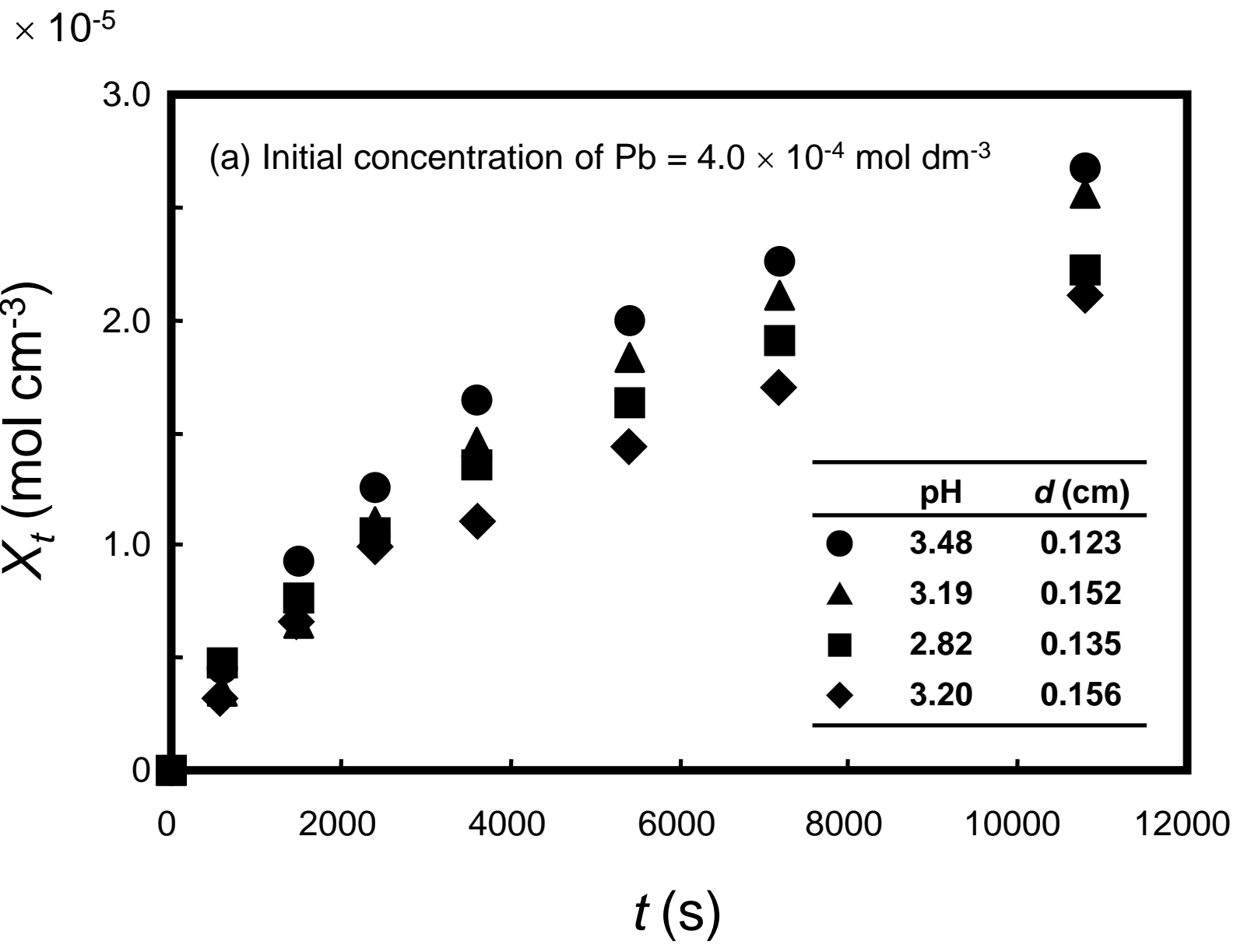

Seki \& Suzuki FIG. 3a. 


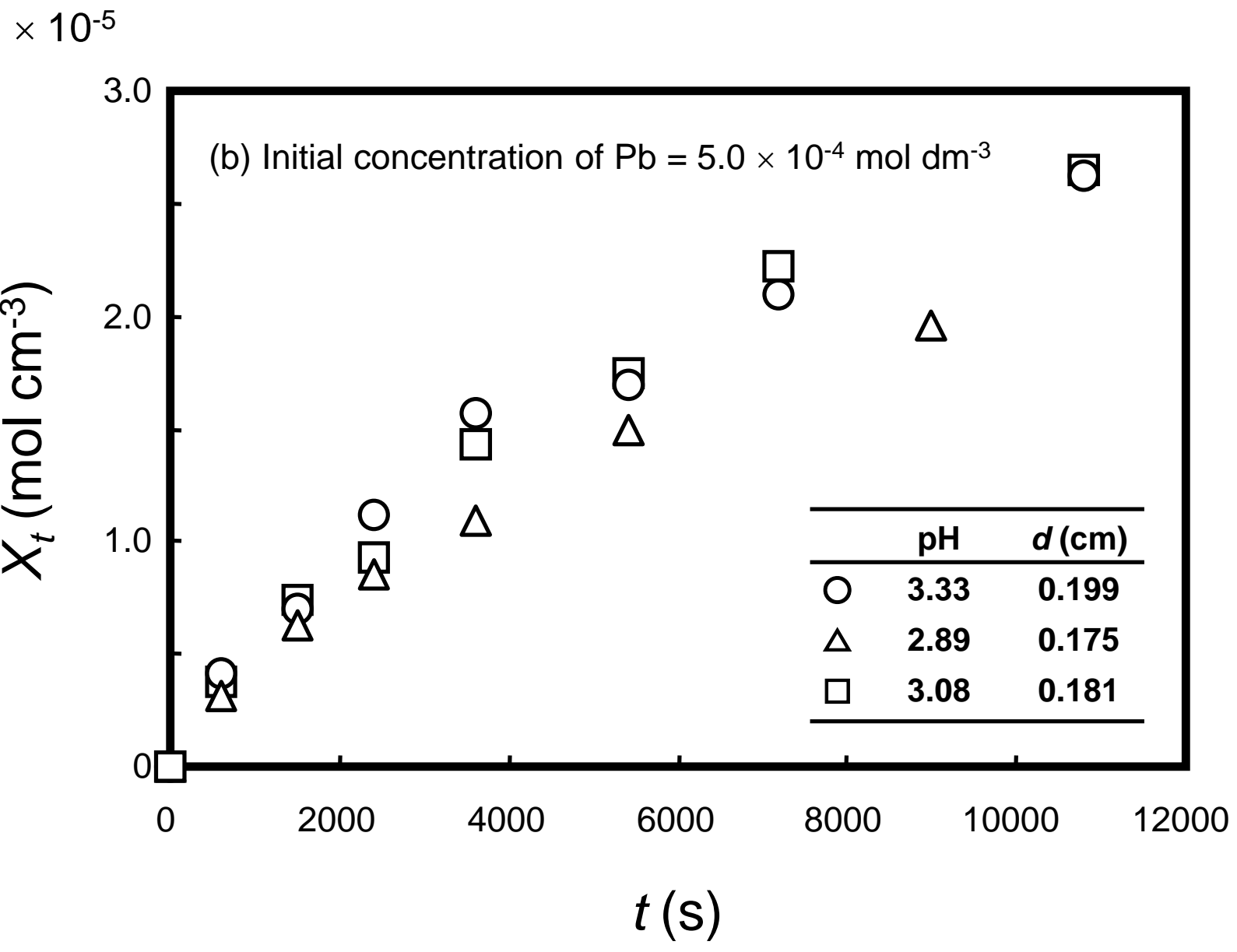

Seki \& Suzuki FIG. 3b. 


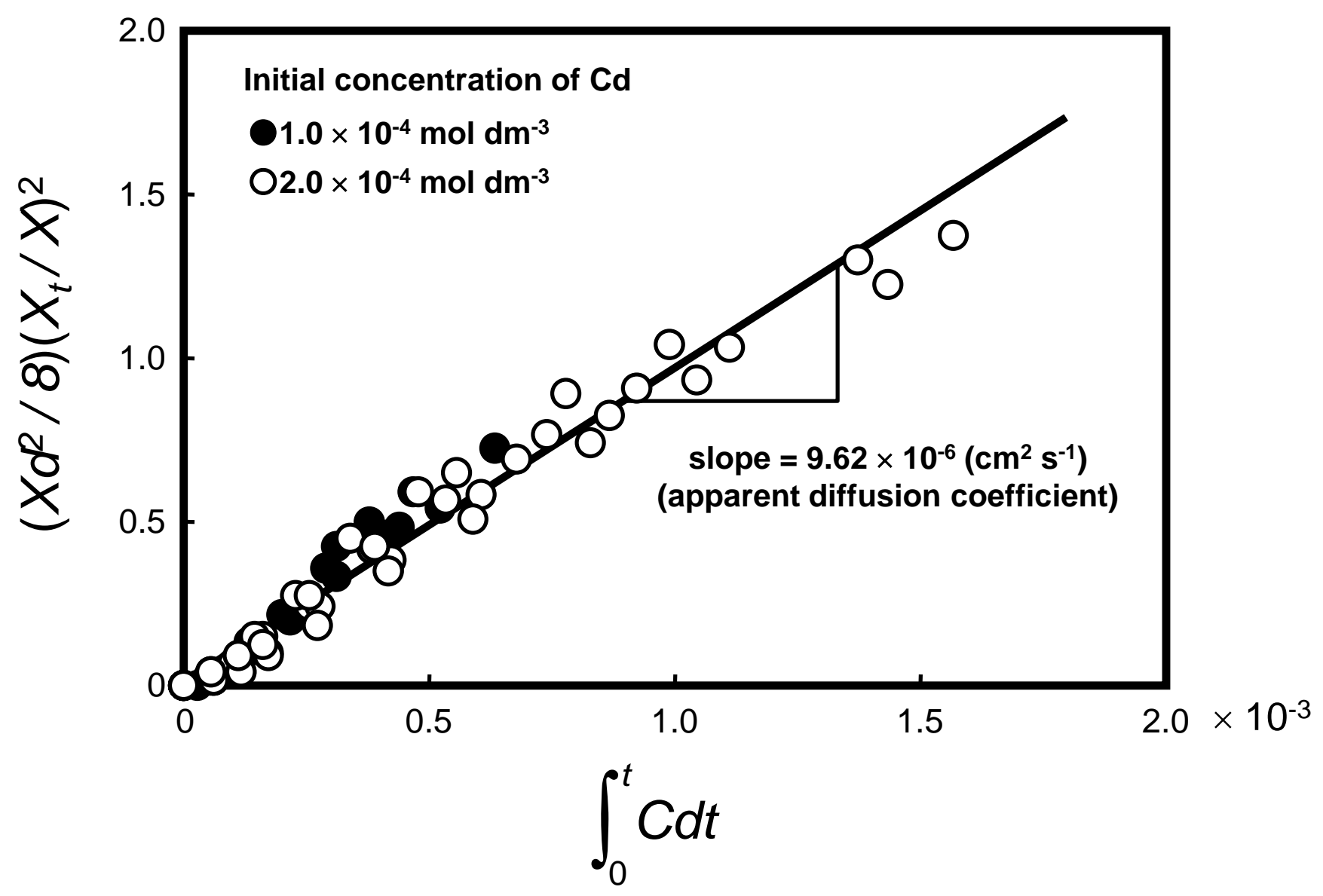




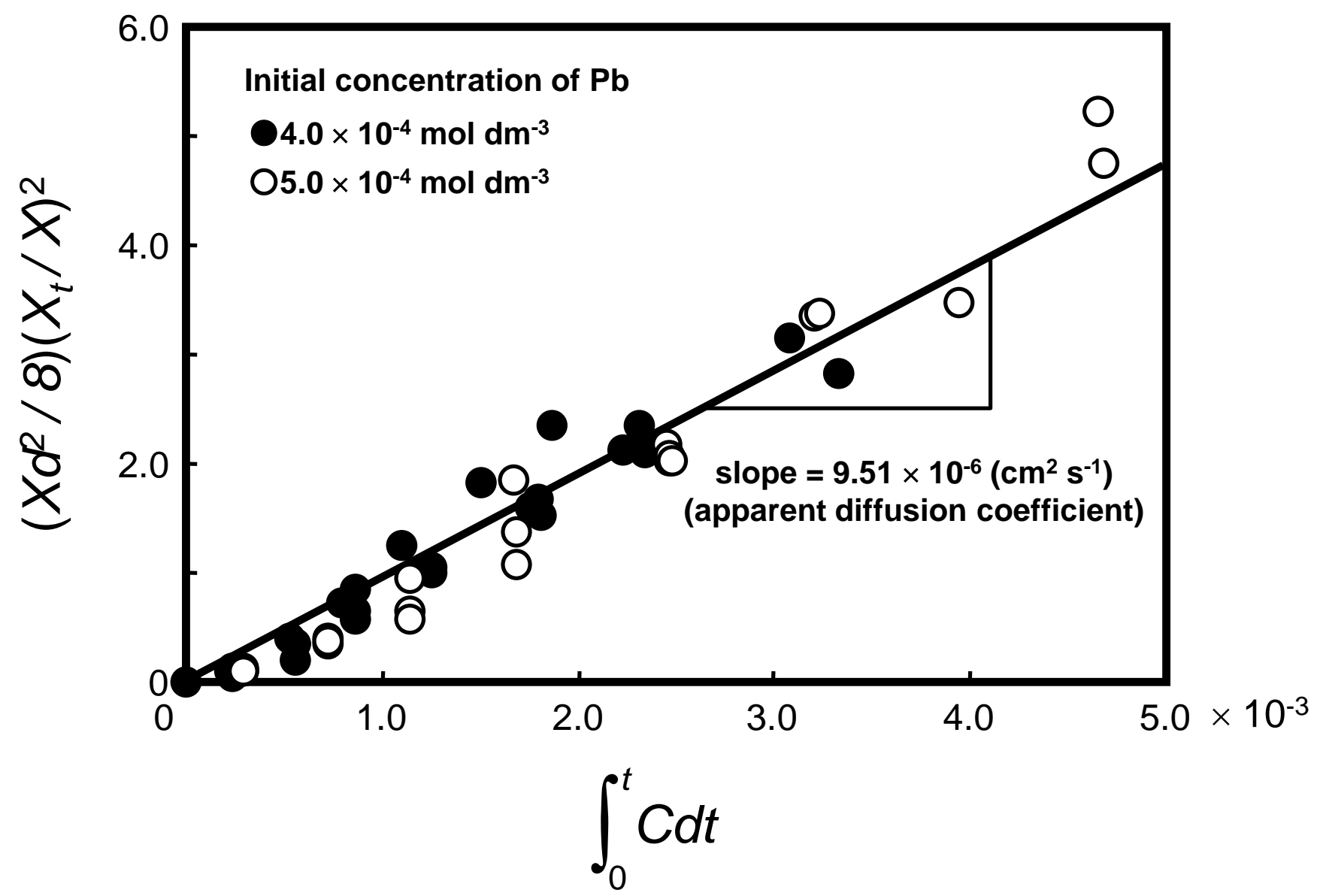

Seki \& Suzuki FIG. 5. 